\title{
Design of Animation Derivative Products and Practice in Animation Major Teaching
}

\author{
Ran Zhao \\ School of Dig ital Arts \\ Dalian Neusoft University of information \\ Dalian, China 116033
}

\begin{abstract}
Animation derivative products mainly refer to various peripheral products derived from television animation, favorite cartoon characters on network and classic animation images in games, which have enjoyed public popularity through their generated IP resources combining with national culture, designers' ideas and ergonomics and motivate people to purchase. The thesis aims to provide creative design ideas for animation derivative products of our country through analysis of various types of products and exploration on cultural, ideological and scientific factors that should be attached attention to when conducting animation major teaching.
\end{abstract}

Keywords-animation derivation; cultural symbol; cultural added value; "benevolence" ideology; advanced technology

\section{INTRODUCTION}

The world has experienced constant changes in right of speech from military-governed to economy-dominant and to culture-expanded types till now with the booming global diversified cultures. Animation industry has been casting increasing beneficial influences on cultural output and economic development, so that animation culture is not only the most profitable project among the entire movie industry, but each derivative products of any animation being released can bring commercial markets and enormous economic profits which is obvious to all. The formal operation of the sixth Disneyland Park in the world - Shanghai Disneyland Park marks that animation derivative products are gradually developing along the way from simplification to diversification and introducing the maturity of the industry. Furthermore, animation theatrical films are getting rid of child ish orientation and stepping into all-age orientation. Clearly, animation derivative product designing is worth more attention and deep researches from us. At such an age when diversified cultures and science competition prevail, major difficulties lie in creating animation derivative products possessing both animation features and national styles, at the same time perfectly integrating characters, scenes, stage properties and other elements for our current researches since the social property and essential property of national and epochal characters. Product designing must become the most effective factors of economic development and cultural consumption to touch customers in the consumption age and animation elements packaging and deigning have been playing an increasingly important role in the entire animation domain. "3B principles" (3B refers to Beauty, Baby and Beast) proposed by advertising master David Ogilvy from the view of creativity happens to coincide with the concept. The definition on animation stated in the thesis originates from the animation characters in television animation, network animation and game cartoons, especially referring to those having been widely spread and possessing popularity and good reputations.

\section{CULTURE SYMBOL REPRESENTED BY ANIMATION DERIVATIVE PRODUCTS}

Guo Qingguang, a Chinese communication sciences professor has pointed out that "symbols have such functions of expression, understanding, conveying and reflection"; moreover, animation symbols, as a significant one among the mass communication systems, have taken the responsibilities of expressing makers'spirits, conveying national and folk culture and motivating audiences' active reflections, etc. The characters' styles of world-famous animations are generally created based on local drawings, folk literature and folk culture, and have made great influences on cultural inheritance and exchanges. The leading role Sheriff Woody of the first 3D movie Toy Story made by Pixar in 1995 is a typical character that represents Western United States passionate cowboy culture, and the other leading role Buzz Lightyear is a symbol of science and modern culture. In addition, black humor peculiar to Pixar is fused into the movie, and the second and third series are brought out after releasing the movie. Meanwhile, tools with Sheriff Woody and Buzz Lightyear's styles are warmly welcomed by American children, and they almost became the most popular toys fond by American children.

Our national treasure panda is shaped as a model of the Kung Fu Panda manufactured by American Dream Works SAG in 2008, and the second and the third section following even adopted more Chinese elements such as shadow puppets, drawing elements and Kung Fu skillfully and at the same time it has weakened the mysterious connotations of Chinese Tai Chi and elucidated it as the "materialization" image of "the envoy of black and white". Then a series of packaging is put forward by cooperating with the famous oatmeal manufacturing enterprise; Minions in the movie Despicable Me being released in 2010 have attracted fans from all over the world and their asymmetric one-eyed model has once been successful in Monsters Inc., the release of the movie obviously has driven the image to another peak, so that the entire toy 
market is suddenly covered with Minions-styled cushions and stuffed toys; meanwhile, the famous manufacturer of inserting toys has also developed series of toys about Minions' plot; In addition, Zootopia put on show in the beginning of 2016 has borrowed many nations' cultural elements in the global scope and following which the electric products, toys and ornaments with Nick's model are widely sold in e-commerce network. As for Chinese animation, in 1960s, after efforts having been taken by the animation masters such as Wan surname brothers, Te Wei, etc. of the last generation, it has generated the Chinese school which has special and typical features and has shown extraordinary talents in animation industry, such successful images as the Monkey King Sun Wukong in Havoc in Heaven and Nezha in Prince Nezha's Triu mph Against Dragon King, all of which originate from the artistic ideology expressions of Chinese paintings, shadow puppets, paper-cut works, New Year pictures and traditional Chinese operas, etc. What's more, Mr. Black's image in the same-name cartoon has stern justice and braveness which is signifying indication of China's social values at that time and has influenced the generation after $80 \mathrm{~s}$ of Chinese a lot by accompanying with them in their childhoods; The little mouse in Shuke and Beita is designed with the integration of all good virtues such as labor glory and taking pleasure in helping people which, with the full-bodied traditional Chinese merit style, has become fashionable for a time and finally deposited into a classic image of a generation. Besides, those classic animation images carried strong national features and made great influences on many Asian well-known animation creators in that generation, including Osamu Tezuka, the creator of Astro Boy. However, because of the restrictions from historic factors and cultural development, though once out national animation works formed gorgeous flowers and generated fruitful results, it eventually failed to grow up and be established to a extensive and luxuriant forest. To make a general survey of Chinese animation derivative products, there are quite few classic, environmental-protection and exquisite peripheral products, but our neighbor countries have been creating successful and popular animation stars like forming movie stars, so that their animation industrial chains are increasingly developed to be maturer and perfecter. Though their experience cannot be copied, we can still learn something from some classic images created by them such as Crayon Shin-chan, Chi-bi Maruko, One Piece and Doraemon, etc. Generally speaking, Chinese animation characters have strong national features and cultural styles but lack of modern elements, while Japanese animation is successful in shaping cartoon characters that are created and adjusted by closely combining with the demands of society. In conclusion, as a collection of symbols, animation images bear the functions of shaping social ideology, and symbols and ideology interweaves with one another and cannot be separated.

\section{SPECIFIC MANIFESTATION OF ANIMATION DERIVATIVE PRODUCT S' PACKAGING DESI GN}

Product designing and packaging designing have gradually completed the transition from the original commodity practicability to a kind of awareness symbols with the development of modern arts. Generally speaking, design process of product packaging consists of five aspects: "design investigation, creative design, design representation, design evaluation and market verification". Since A merica and Japan have formed their own developed and mature animation industrial chains, designing of animation derivative products for some famous and popular characters have been completed while releasing the original television animations. After summarizing the features of animation derivative products, it can be divided into the following several types.

\section{A. Isomorphic Product Design}

Isomorphic product design indicates that way to utilize the meanings of animation elements and product features to conduct construction design, which is, to combine products with completely irrelevant symbols and "Isomorphic" refers to fulfilling isomorphism between animation figures and packaging container and commodities. Taking the cartoon work Doraemon jointly created by Japanese cartoonists Minako Hujimoto and Abiko Motoo as example, peripheral products about Doraemon has a long history and various types. As shown in Figure 1, the product combines Doraemon head with telephones and applies elements of four-dimensional bags as telephone buggy bags which contain double meanings. The integral shape of telephone is designed as the round head of Doraemon, and screen and keyboard of the phone are visible once opening the head. The phone is equipped with special and dedicated buggy bags which are designed as four-dimensional space of Doraemon and when entirely opening the packaging box, it is able to see the lively and interesting head of Dorae mon as if it is observing the surrounding environment. In addition, a kind of limited essential oil is designed as Doraemon's image and contains some stage properties such as microphone and the little special agent appearing in Doraemon cartoon. Moreover, the package of the product is designed as a music box to create a harmonious and uniform style in the whole, and the facial mask products inside are designed based on the image of time machine in Doraemon cartoon, which implies that a magic effects can be brought to make your skin brighter and younger by using the product which can cast amazing regeneration power to your face. In addition, the product is cleverly and creatively designed to satisfy the customers' good tastes and audiences' psychology, which is, also an application direction of isomorphism in product packaging design. Besides, packaging designs on the derivative products of the series cartoon Mr. Black, for example USB with the image of Mr. Black, use popular plastic transparent and cylinder moulds to dis play Mr. Black's images and also the cylinder design is used in the bottom for creating a sense of stability and safety so as to indicate that the product is able to keep important date information safe and avoid information disclosure. It has gradually formed a new tendency of developing the packaging design of animation derivative products that fusing product designers' spirits and cultural expressions into customer's consumption experience "Fig. 1". 

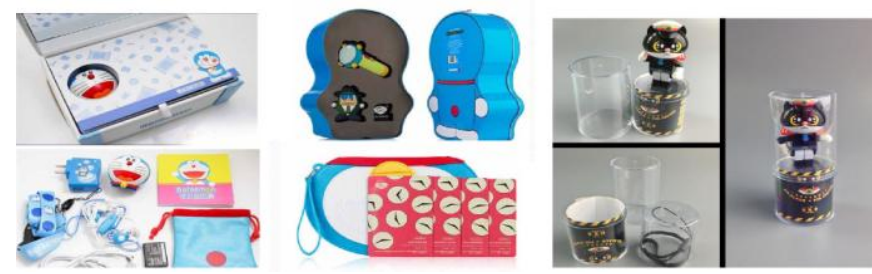

Fig. 1. Isomorphic product design of Doraemon and Mr. Black

\section{B. Design of Children Products}

Children-oriented product designing has always been the main market under violent co mpetition of animation derivative products. Since children are the direct and major customers of animation works, gaining popularity and fondness from children is equivalent to winning the market. In such case that there are excessively various children-oriented products which generally include basic necessities of life and education necessities, etc., but majority of children-oriented product designing is to simply print animation images on the package of products. Actually, pouring more creativity into product designing may bring interests and favor degree to customers. A lively example is that Japan's Tohato cookies do not simply print the image of Crayon Shin-chan in the package but take Shin-chan's favorite star cookies as the model of design entry point which can bring a sense of plot identification to children and appeal to the consumption group of children.

\section{Packaging Design of Modeling Products}

The so-called packaging design of modeling products is to conduct the production of characters through directly using the models and characters in animation works or changing the original the proportion of body and head to the ACG style, for example, Chi's modeling ornaments, key chains and stuffed toys, etc. in マッドハウス (Chi's Sweet Home), and the most popular are the four kinds of Chi's tools that cute Chi, angry Chi, happy Chi and poor Chi designed by the magnate of fast food industry according to the character, and the products are elaborately designed. The tools can get flushed face, and have flashing in their red hearts and can cry, which enables the products to be crazily purchased once appearing in the market and have attracted many toy collectors' attention and interests, so that it achieves win-win situations in both commercial benefits and animation derivative products' elaborate designs. In addition, the Chinese original animation image Ali is widely known by the public through expression packages in the network communication applications, after Ali is accepted and enjoys its popularity by lots of people, the emptiness at domestic animation derivative product designing is suddenly full with by the creative image which marches towards commercial market. In recent years, the domestic original animation gradually regain faith and confidence of the public, transferring from baby-oriented cartoons such as Happy with the Gray Wolf, Boonie Bears to the aestheticism style like Little Door-god to phenomena movies like Herois back. Furthermore, the industrial chains become maturer and healthier so that richer and richer styles appear and it has successfully conducted cooperation with a hot of international brands.

\section{PRACTICE IN ANIMATION MAJOR TEACHING}

Long terms of experience summarized on animation major teaching has proved that nowadays, when it springs up with multiple social ideological trends and people are increasingly pursuing individual and diversified development, are witness the qualitative change of consumption model from material consumption to cultural consumption. The famous psychologist Abraham Maslow has pointed out five levels of people's demands: physiology, safety, identification, esteem and self-actualization, which requires us to fuse much awareness such as culture, idea, quality, environmental protection and science and technology, etc. into designing of animation derivative products.

\section{A. Stressing on Cultural Added Value}

World-famous "Barbie" dolls have been widely sold for half century and have become typical symbol of A merican culture as same as Mickey Mouse and Coca-cola. Moreover, Chinese culture and art have a long history and diversity in their styles. Thereinto, abundant and profound cultural deposits contained in lots of elements such as Chinese shadow puppet, paper-cut, sculpture and ink and wash painting, etc. have generated extremely powerful vitality and influences beyond time and space. With the coming of economic society, people's consumer demands have stepped a great leap from material pursuing to the spiritual level. Therefore, we should lay emphasis on motivating students to deeply study on Chinese cultural arts and combine with customers' aesthetic tastes, life tastes, cultural attainment, etc. and integrate such knowledge theories as chromatics, design psychology, modern design aesthetics and so on to explore an innovative way of the combination between traditional Chinese national and folk culture and Chinese animation elements so as to increase the cultural added value of animation derivative products, by which traditional arts can be developed and modern civilization can be expressed. Moreover, it is possible for us to manifest our nation cultural connotation and inherit the special aesthetic conception. Therefore, animation major students are required to integrate the cultural essence of our nation when creating animation products which has the similar spirit with an old saying of Lu Xun that "What ethnic is what worldwide".

\section{B. Communication of "Benevolence" Ideology}

The essence of Chinese Confucian culture lies in "benevolence" ideology, namely "views vary from person to person", and "human-hearted man is invincible". Plain speaking, it means that to convey designers' mental realm s to customers and to take adequate consideration of ergonomics and using feelings of customers during product designing. The process of science and technology progressing and digital time developing has witnessed enormous changes in product design concepts from self-expression, environmental integration to spiritual tastes. Pursuit on humanization is, from the aspect of enterprise competition, to promote enterprise images and product popularity; and fro $m$ the aspect of social development, is the symbol of improvement of people's life standard and quality and reflection of social civilization progressing. Besides, selecting environmental-protection materials also is an expression of "benevolence" to the nature. "Benevolence" 
ideology should be followed throughout animation major teaching and the entire design process of animation derivative products.

\section{Advanced Technology}

As the traditional two-dimensional animation has been able to complete by computer, animation has experienced a long developing process from traditional freehand sketching, computer animation, three-dimensional computer animation, 3D movies, 4D movies, holographic laser projection and naked eye projection, etc. Following the constant development of communication technology, digital technology, 3D printing technology, virtual reality technology and augmented reality technology, modern technologies should be fully used in the class teaching of animation major, for example, the designed products can be set models through digital technology and three-dimensional technology and then be printed by 3D printing technology to preview the proportion, quality of animation role models and product modeling effects. Meanwhile, bringing new technology into classes will motivate students' creativity and interests and fulfill teaching benefits both students and teachers.

\section{CONCLUSION}

In conclusion, contemporary designs of animation derivative products gradually show their amazing grace and commercial effects. Only through integrating national culture, contemporary artistic design styles, market analysis of consumer groups, creative methods of product design and technique of expression in animation major teaching, the organic combination of culture and business can be achieved with an innovative posture.

\section{REFERENCES}

[1] Guo Qingguang. "Teaching Guide of Communication", Renmin University of China Press, June 2007, p46.

[2] Li Tao. "Research on American and Japanese Century Animation Image", Guangming Daily Press, 2008, p 41-46.

[3] Cai Kezhong, Zhang Zhihua. Package Design in the Digital Age, Packaging Engineering, 2004 Vol. 25, No.6, p81-188.

[4] Yi Yanbo, Jiang Guanqun. Figurative Form Show of Comics in the Package Design, "Grand Sight of Arts", 201 1, No. 8, p144. 